\title{
A survey on genetically modified maize in foods commercialised in Portugal
}

\author{
Telmo J.R. Fernandes ${ }^{\text {a }}$, Joana S. Amaral ${ }^{\mathrm{a}, \mathrm{b}}$, M. Beatriz P.P. Oliveira ${ }^{\mathrm{a}}$, Isabel Mafra ${ }^{\mathrm{a}, *}$ \\ ${ }^{a}$ REQUIMTE, Departamento de Ciências Químicas, Faculdade de Farmácia, Universidade do Porto, Rua de Jorge Viterbo Ferreira, 228, \\ 4050-313 Porto, Portugal \\ ${ }^{\mathrm{b}}$ ESTiG, Instituto Politécnico de Bragança, Campus de Sta. Apolónia, 5301-857 Bragança, Portugal
}

\section{A R T I C L E I N F O}

\section{Article history:}

Received 27 May 2013

Received in revised form

11 July 2013

Accepted 15 July 2013

\section{Keywords}

GMO detection

Zea mays $\mathrm{L}$.

Processed foods

Real-time PCR

Quantification

\begin{abstract}
A B S T R A C T
Maize, the second most important genetically modified (GM) crop, has the highest number of authorised GM events for food and feed in the EU. To provide consumer's information, labelling for food products containing more than $0.9 \%$ of GM material is demanded by the actual EU legislation. Analysis of foods is then essential to detect and quantify GM maize material and verify the compliance with labelling information. The aim of the present work was to assess the presence of GM maize in a range of processed foods commercialised in Portugal between 2007 and 2010. For this purpose, screening of GM material was carried out by qualitative PCR targeting the $35 \mathrm{~S}$ promoter and the NOS terminator, followed by the specific detection of Bt11, MON810, Bt176, GA21, MON863, NK603, TC1507 (also known as DAS1507), DAS59122 and MIR604 events. The identified maize events were confirmed and quantified by real-time PCR with hydrolysis probes. The overall results of GMO screening were $30 \%$ for 35 S promoter, $10 \%$ for NOS terminator and $25 \%$ for identified events. The most frequently detected events were MON810, TC1507 and NK603, with one sample containing GA21, while the other events were not detected in any of the analysed foods. The quantitative results suggest the need for a more severe control since $4 \%$ of the analysed foods contained more than the threshold for labelling and none of them declared the presence of GMO.
\end{abstract}

(c) 2013 Elsevier Ltd. All rights reserved.

\section{Introduction}

During the past two decades, the progress of biotechnology has rendered the farmers to adopt the cultivation of genetically modified (GM) crops agronomic characteristics of interest. Despite the controversies surrounding genetically modified organisms (GMO), their cultivation has been steadily increasing since the first commercialised crop in 1996. In 2012, 170 million hectares were occupied by biotechnological crops, from which maize accounted for 33\% (James, 2012). Portugal was included in the 28 countries planting GM crops in 2012, ranking the 22nd position (James, 2012) with approximately 5 thousand hectares of GM maize produced, for both food and feed, in 2011 (Agência Portuguesa do Ambiente, 2013). Maize, the second most important GM crop, has the highest number of authorised transgenic events for food and feed in EU (GMO Compass, 2013).

\footnotetext{
* Corresponding author. Tel.: +351 220428640; fax: +351 226093390.

E-mail address: isabel.mafra@ff.up.pt (I. Mafra).
}

Ever since the GMO entered the food chain, the EU has dedicated special attention to consumer information by requiring compulsory labelling for food products containing more than $0.9 \%$ of GM material (Regulation (EC) No. 1829/2003). Thereby, to guaranty the implementation of legislation, analytical methodologies allowing accurate determination of GMO are demanded. The most accepted methods for GMO detection rely on DNA analysis using polymerase chain reaction (PCR) because of the superior stability of nucleic acids compared to proteins. The high specificity, sensitivity and reliability of PCR techniques, enabling the quantification of minute amounts of GM material even in highly processed foods are also main advantages (Gryson, 2010; Mafra, Ferreira, \& Oliveira, 2008). Real-time quantitative PCR represents the most powerful means of quantifying GM material in agricultural and food products. It allows the continuous monitoring of the amplification products by the measurement of fluorescent signals. The use of specific-sequence fluorescent probes, such as the hydrolysis TaqMan probes, is the most frequently applied approach for GMO analysis as recently reviewed by Mafra (2011).

The need to monitor and verify the presence of biotechnologyderived material in foods has prompted the development of 